\title{
PERSISTENT TRIGEMINAL ARTERY
}

\section{Angio-tomography and angio-magnetic resonance finding}

\author{
Lícia Pachêco Pereira', Lara A.M. Nepomuceno', Pablo Picasso Coimbra², \\ Sabino Rodrigues de Oliveira Neto ${ }^{2}$, Marcelo Ricardo C. Natal ${ }^{3}$
}

\begin{abstract}
The trigeminal artery (TA) is the most common embryonic carotid-vertebrobasilar anastomosis to persist into adulthood. It typically extends from the internal carotid artery to the basilar artery. Persistent primitive arteries are usually found incidentally, but are often associated with vascular malformation, cerebral aneurysm and, in case of TA, with trigeminal neuralgia. We present one patient with TA as a cause of trigeminal neuralgia and in other three as an incidental finding, on TC and MR angiograms.
\end{abstract}

KEY WORDS: trigemital, artery, computed tomography, magnetic ressonance, angiogram.

\section{Artéria trigeminal persistente: achado na angio-tomografia e angio-ressonância magnética}

\begin{abstract}
Resumo - Artéria trigeminal (AT) é a anastomose carótido-vertebrobasilar mais comum a persistir na vida adulta. Tipicamente estende-se da artéria carótida interna até a artéria basilar. Artérias primitivas persistentes são usualmente um achado incidental, mas freqüentemente estão associadas a malformações vasculares, aneurismas e, no caso da AT, a neuralgia do trigêmio. Apresentamos um paciente com AT como causa de neuralgia do trigêmio e em outros três como um achado incidental, em angiogramas por tomomografia computadorizada e ressonância magnética.
\end{abstract}

PALAVRAS-CHAVE: trigeminal, artéria, tomografia computadorizada, ressonância magnética, angiograma.

Persistent trigeminal artery (PTA) is the most common primitive carotid basilar anastomosis that persists in adulthood. It goes from the internal carotid artery (ICA) to the basilar artery, at the level of the cavernous sinus ${ }^{1-4}$. It reaches the basilar artery in two ways: in $50 \%$ of cases, it penetrates the sella turcica, runs in its own groove and perforates the dura near the clivus to then join the basilar artery between the anterior inferior cerebellar arteries and the superior cerebellar arteries. In the other $50 \%$, the trigeminal artery leaves the cavernous sinus, courses with the trigeminal root, or runs between the sensory trigeminal root and the lateral side of the sella in a groove of the posterior petrosal process to join the basilar artery between the origins of the anterior inferior cerebellar arteries and the superior cerebellar arteries'. In most cases it is an incidental finding, but may be associated with malformations, aneurysms or anomalies in other blood vessels. Patients may be asymptomatic or present symptoms due to low flow of posterior circulation or carotid microembolization from posterior circulation ${ }^{2-3}$. Yet, PTA can cause trigeminal neuralgia ${ }^{5,6}$.

The purpose of this study is to demonstrate the trigeminal artery in angio-computed tomography (angio-CT) and magnetic resonance imaging-angiography (angio-MRI), emphasizing its anatomical relationships, in four patients.

\section{CASES}

Cases 1 and 2 (para-selar course)

Case 1- A 56-year-old woman presented with a 5-year history of right persistent facial pain defined as electric shock-like episodes in areas supplied by the trigeminal branches. No neurological deficit was found on examination. Angio-MR (high-resolution 3D T1 weighted gradient eco sequence and 3D TOF technique on a 1,5 Tesla MR unit) and maximum intensity projection

\footnotetext{
'Resident Physician of the Radiology Department of Fortaleza General Hospital (Hospital Geral de Fortaleza - HGF), Fortaleza CE, Brazil; ${ }^{2}$ Specialist title/Brazilian College of Radiology (Colégio Brasileiro de Radiologia - CBR), Assistant Physician of Radiology Department - Fortaleza General Hospital (Hospital Geral de Fortaleza - HGF), Fortaleza CE, Brazil; ${ }^{3}$ Specialist title/Brazilian College of Radiology (Colégio Brasileiro de Radiologia - CBR), Assistant Physician of Radiology Department - Hospital de Base, Brasilia DF, Brazil.
} 
(MIP) in three planes were performed, showing the origin of PTA arising from the posterolateral aspect of cavernous segment of right internal carotid artery. It coursed postero-inferiorly around the lateral side of the sella, near the sensory trigeminal root to communicate with basilar artery in the prepontine cistern, between the origins of the anterior inferior cerebellar arteries and the superior cerebellar arteries. (Fig 1) The patient was treated conservatively with anti epileptic drugs.

Case 2 - A 55-year-old-woman with a previous diagnosis of cerebral vasoconstriction syndrome. Angio-MRI performed after a new episode of a strong intensity holocranian headache, which showed the presence of PTA as an incidental finding, without further changes (Fig 2).

\section{Cases 3 and 4 (intra-selar course)}

Case 3 - Woman of 83 years, with symptoms of dementia, underwent to a CT angiography (64 Multi-slice detector), which demonstrated the PTA as an incidental finding. In this case, it

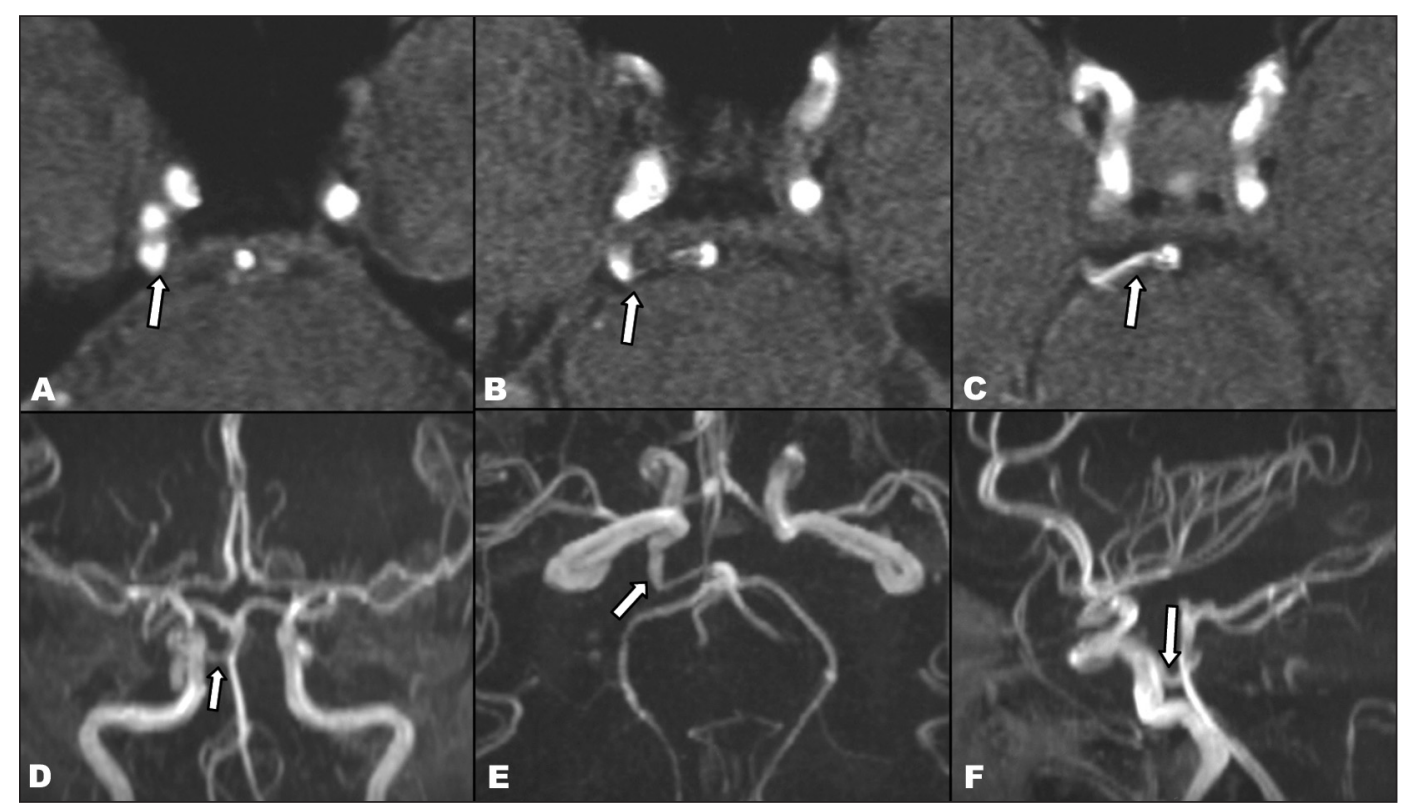

Fig 1. [A-C] Axial T1 showing PTA (arrows) coursing postero-inferiorly between the lateral side of the sella and the sensory trigeminal root. [D-F] MR angiography MIP projections showing PTA (arrows) arising from cavernous ICA to join the basilar artery.

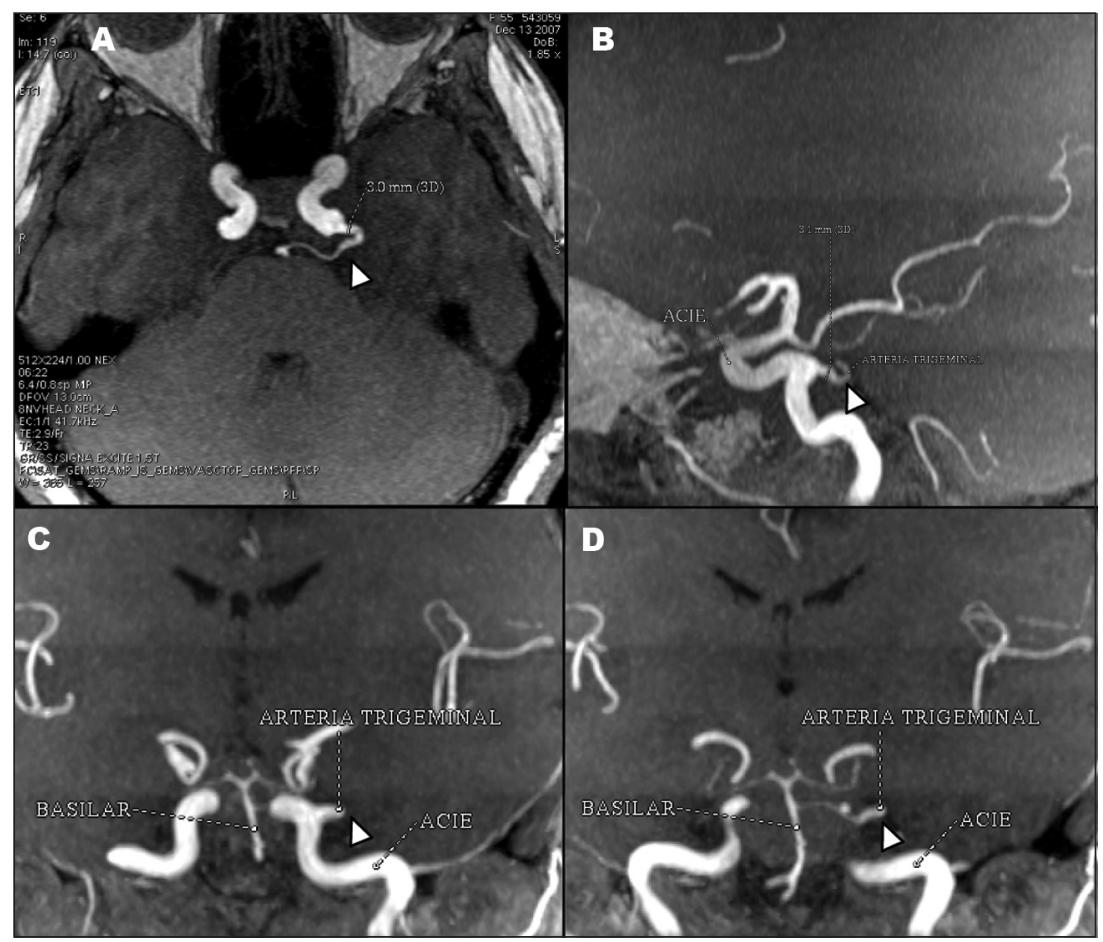

Fig 2. MR angiography, axial [A], sagittal [B] plans and contiguous coronal $[C, D]$, demonstrating the communication between the left internal carotid artery, level of the posterior knee, in the cavernous portion, and basilar artery (arrowheads). Note the paraselar course. 


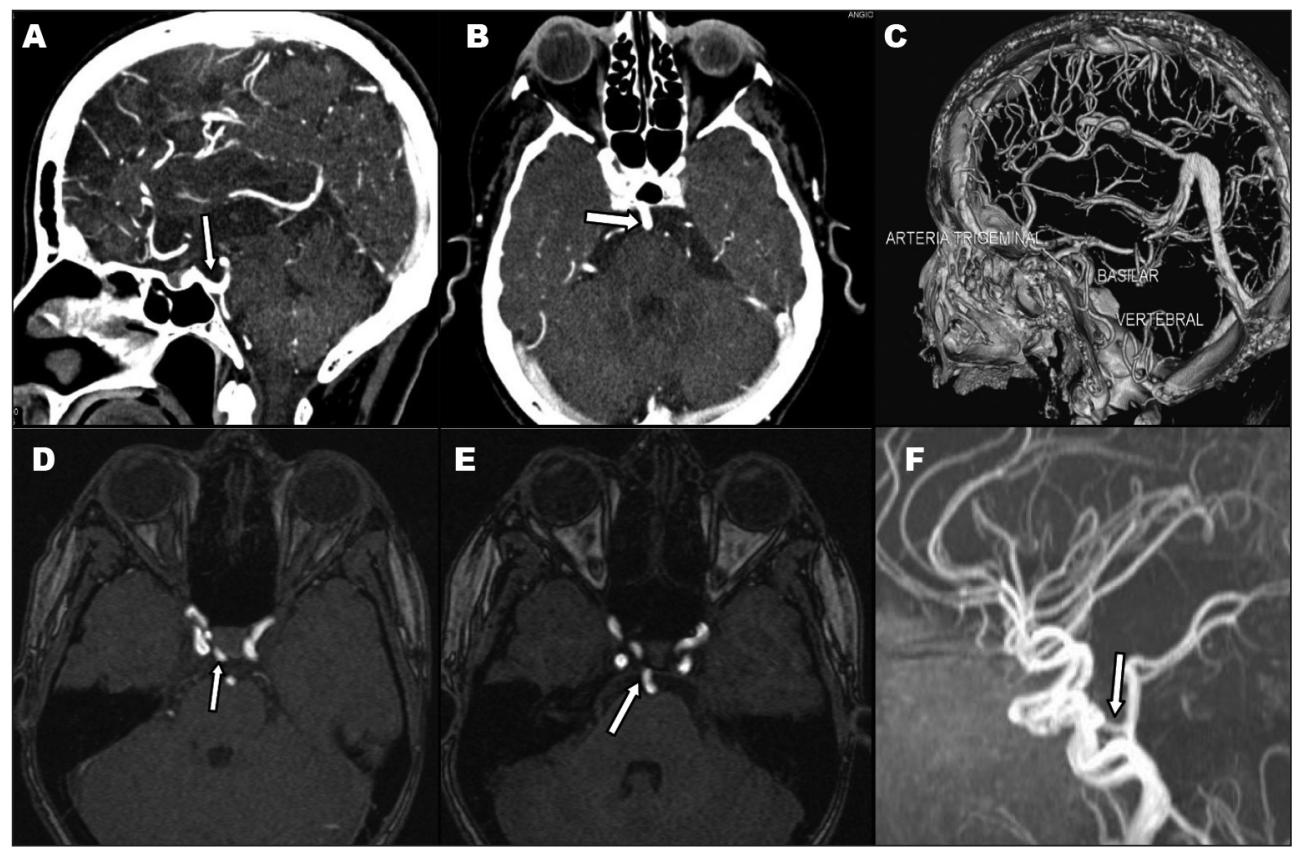

Fig 3. PTA intraselar course. CT angiography sagittal [A] and axial [B] plans and 3-D reconstruction [C] and Angio-MRI in other case [E-F] demonstrating the PTA (arrows) following an intraselar course.

penetrates the sella turcica and perforates the dura near the clivus to join the basilar artery between the anterior inferior cerebellar arteries and the superior cerebellar arteries (Fig 3A-C).

Case 4 - Woman, 23 years old, with venous sinus thrombosis six years ago and chronic headache, MR angiography (Fig 3 D-F).

\section{DISCUSSION}

During the intracranial vascular development in the embryo (approximately 35 days of gestational age), four main temporally anastomosis arise between carotid and vertebral-basilar systems: the trigeminal, optical, hypoglossal and proatlantal intersegmental ${ }^{1-4}$. These anastomosis persist for about 1 week and disappear with the subsequent development of posterior communicants and vertebral arteries'. Occasionally, they persist after birth and adulthood, and the trigeminal artery is the most common $^{1,2}$, representing about $85 \%$ of these primitive persistent anastomosis. (1) The reported incidence is about $0.2 \%$, however, considering the cases not diagnosed and not reported, the impact probably reaches $3 \%$. It originates from the cavernous portion of the internal carotid artery in the posterior knee and may course paraselar or intraselar downward to join with the upper third of basilar artery. It is classified by Saltzman in type 1, when it joins the basilar artery between the superior cerebellar arteries and the anterior inferior cerebellar arteries. The basilar artery proximal to the junction is usually hypoplastic and the posterior communicating arteries are absent or poorly opacified. The trigeminal artery supplies both posterior cerebral arteries and superior cerebellar arter- ies. The Saltzman type 2 it also joins the basilar artery between the superior cerebellar arteries and the anterior inferior cerebellar arteries but the posterior communicating arteries are present and supply the posterior cerebral arteries. Saltzman type 3 is referred to the trigeminal artery variant when it directly joins to a cerebellar artery'. The PTA is generally described as an incidental finding and is associated with various vascular anomalies, such as aneurysms of the polygon of Willis, agenesis of the carotid and vertebral arteries, facial hemangiomas, no posterior communicating artery disease, moyamoya, abnormalities of the vessels of the aortic arc, carotid-cavernous fistulas, arterial-venous malformations, brain tumors, cerebellar ischemia and trigeminal neuralgia ${ }^{2,4,5}$. The prevalence of a PTA in patients with trigeminal neuralgia is $2.2 \%$, in a study performed by Bondt et al. and neurovascular compression was assumed to be present if the patient showed clinical features of trigeminal neuralgia, if there was contact between an artery and the trigeminal nerve on the affected side, and if other pathology had been excluded ${ }^{8}$. The PTA is easily identified by MR angiography, however, the exact location of the drilling of the skull base is impossible to be identified by these methods ${ }^{3}$. Small trigeminal arteries cannot be identified in spin-echo $\mathrm{T} 1$ and $\mathrm{T} 2$ sequences, it is only possible with the MR angiography ${ }^{6}$. Patients with PTA associated with vascular malformation, cerebral aneurysm or trigeminal neuralgia may need surgical treatment. Therefore, the relationship of these vessels with the skull base must be well characterized, and $\mathrm{CT}$ angiography is a good method for simultaneous visu- 
alization of bone and vascular structures ${ }^{3}$. Moreover, recognizing these vessels before endovascular procedures is of great importance in accessing the risk of emboli passing through these vessels during embolization therapies. As the blood flows from carotid to the vertebro-basilar system, there is the risk of cerebellum and brainstem ischemia by emboli from an ulcerated plaque in the carotid bifurcation. It is also essential that these vessels are not improperly handled during surgical procedures in the posterior fossa, preventing hemorrhage and ischemia ${ }^{4}$.

\section{REFERENCES}

1. Luh, GV, Dean, BL, Tomsick, TA, et al. The persistent fetal carotid-vertebrobasilar anastomoses. AJR Am J Roentgenol 1999;172:1427-1432.

2. Eluvathingal Muttikkal TJ, Varghese SP, Chavan VN. Persistent trigem- inal artery and associated vascular variations. Australas Radiol 2007; 51:31-33.

3. Suzuki $Y$, Kunii N, Matsumoto K. Persistent primitive trigeminal artery imaged by three-dimensional computed tomography angiography: two case reports. Neurol Med Chir. 1999;39:748-751.

4. Ali S, Radaideh MM, Shaibani A, Russell EJ, Walker MT. Persistent trigeminal artery terminating in the posterior inferior cerebellar artery: case report. Neurosurgery. 2008;62:746-748.

5. Chidambaranathan N, Sayeed ZA, Sunder K, Meera K. Persistent trigeminal artery: a rare cause of trigeminal neuralgia - MR imaging. Neurol India 2006;54:226-227

6. Uchino A, Kato A, Takase Y, Kudo S. Persistent trigeminal artery variants detected by MR angiography. Eur Radiol 2000;10:1801-1804.

7. Saltzman GE, Patent primitive trigeminal artery studied by cerebral angiography. Ada Radiol 1959;1:329-336.

8. de Bondt BJ, Stokroos R, Casselman J. Persistent trigeminal artery associated with trigeminal neuralgia: hypothesis of neurovascular compression. Neuroradiology. 2007;49:23-26. 